\title{
Factors of civil identity formation in life safety training
}

\author{
G.S. Kamerilova ${ }^{1 *}, M . A$. Kartavykh$^{2}$, and M.A. Gubareva ${ }^{3}$ \\ ${ }^{1}$ Minin Nizhny Novgorod State Pedagogical University, Nizhny Novgorod, Russia \\ ${ }^{2}$ Minin Nizhny Novgorod State Pedagogical University, Nizhny Novgorod, Russia \\ ${ }^{3}$ Minin Nizhny Novgorod State Pedagogical University, Nizhny Novgorod, Russia
}

\begin{abstract}
The article is devoted to the study of the factors of the formation of civil identity in a general education organization when teaching life safety. Detailed analysis and comparison of the leading approaches to the study of this issue in the scientific literature are carried out. The author generalizes and systematizes numerous factors that influence the formation of civil identity. Their level character (global, national, personal), objectivity and subjectivity of manifestation, the positive and negative orientation of influence, dialectics in revealing the essence of influence are established and disclosed. A special role is given to education in the field of life safety, which is considered based on modern survey and design methods that are important for scientific analysis and reflection. The conducted survey of teachers of the Nizhny Novgorod region allows us to establish and evaluate their attitude to civil identity and the possibility of its formation in life safety training. The implementation of educational projects in the study of life safety in the classroom and extracurricular activities, allows you to form a stable motivation and civic qualities of the individual - the fundamental basis of civic identity.
\end{abstract}

\section{A problem statement}

The socio-cultural context of the modern era, characterized by globalization, digitalization, multiculturalism, high dynamism, and increasing threats and social risks, has a significant impact on the personal development of the younger generation. The current and powerful challenge of the time is the formation of civil identity, the crisis of which is widely discussed in the socio-cultural and scientific-pedagogical literature (A.G. Asmolov, E. Erikson, V.A. Tishkov, R.G. Abdulatipov, J. Kellas). Teenagers and young people who are in search of their place in the public space, understanding the role and purpose in society, face serious difficulties of self-determination. The rapidity of sociocultural changes requires them to quickly restructure the main components of civic identity, allowing them to adequately respond to new ideas, values, and goals. It is noted not only the confusion of adolescents and young people in a complex and insecure world but also the lack of a strong

${ }^{*}$ Corresponding author: prof-ped.gpa@mail.ru 
value and ideological foundation that determines a conscious individual choice. The resolution of this contradiction is connected, first of all, with the identification of the leading factors of the formation of civil identity among students of general education organizations when teaching life safety. It is known that the success of solving any problem situation, including in the field of ensuring the development of self-consciousness of the individual as a citizen of a multicultural society, largely depends on the establishment of its causes and prerequisites, which are the main problem of our study. The systematic representation and consideration of the factors of the formation of civil identity will allow us to formulate a new scientific vision of the problem and to reveal the insufficiently used potential of the course «Fundamentals of Life Safety» in educational practice.

\subsection{The objective of the work}

The purpose of the work was to identify and systematize the leading factors of the formation of the civil identity of the individual, which is revealed in the training of life safety in primary and secondary schools. The achievement of the goal required reference to the works of researchers (R.G. Abdulatipov, R.F. Barash, R.F. Bemalyan, A.S. Galchenko, A.V. Gulevich, M.S. Guseltseva, A.V. Rudakov, V.A. Tishkov, I.A. Tyagunov, E. Erikson, O.N. Yanitsky) dealing with the methodology and general theoretical issues of the problem under consideration $[1,2,3]$. The works of S.V. Abramova, L.V. Bayborodova, and V.N. Yushchenko were in demand. Moshkin, S.V. Petrov, V.P. Solomin, P.V. Stankevich, which considered the issues of the above-mentioned problem in the framework of the educational field «Life Safety» $[4,5,6]$. The theoretical approaches developed by the authors form the basis of this study, which is aimed at understanding new pedagogical realities in the formation of civil identity, taking into account the identified and systematized factors and features of modern life safety training. This made it possible to enrich the theory and methodology of life safety training with results and conceptual provisions that have pedagogical expediency.

\section{Results of the research}

To achieve this goal, the following tasks were set and solved in the study:

- identification of the essence of civic identity and its growing importance in the sustainable development of Russia, the role of life safety education in its formation;

- analysis of the theory and practice of considering the factors of the formation of civic identity in the political sphere, sociology, psychology, pedagogy, and methods of teaching life safety;

- systematization of factors of formation of civil identity and identification of opportunities for their consideration in the educational process of an educational organization;

- development of ways to implement the most effective factors in the system of life safety training;

- conducting analytical and reflexive research using survey and design methods that provide disclosure of the research topic.

The phenomenon of civil identity is revealed based on its multi-valued essence and aspect consideration. The psychological aspects of civic identity reflect the ideas of an integral personality, identical to itself, in relations with the surrounding world (N.S. Burlakova, V.I. Oleshkevich, Yu.R. Efremova, V.V. Znakov), realizing its basic needs by realizing its belonging to a certain community [7, 8, 9]. This interpretation is supplemented by a socio-cultural aspect, which characterizes it as a dynamic process of understanding a 
person's belonging to a certain socio-cultural community of people. Having a syncretic nature, civil identity includes ethnic, political, confessional, and social types that form its fundamental foundations. Structurally, civic identity is the unity of the following components: 1) axiological, which determines the value relations of a person in a situation of self-determination; 2) cognitive, represented by a system of knowledge about one's sociocultural community; 3) praxiological, meaning active social activity and behavior under one's civic position, including dialogical interaction; 4) emotional, allowing one to perceive one's identity positively, to cooperate benevolently and tolerantly with people of another culture. Civil identity plays a huge role in the formation of civil society, achieving social harmony in the country, ensuring inter-ethnic trust as a condition for a dialogue of cultures in a multinational Russian society.

Education is an effective factor in the formation of civic identity $[10,11,2,12]$, expressing global consolidating trends. A special role is given to education in the field of life safety, reflecting the leading positions of civil identity [13]. The educational material on ensuring social security and the basics of military service in Russia, which is mastered by students with the help of modern pedagogical technologies, serves as a substantial basis. The formed civic identity ensures the success of self-determination, overcoming social conflicts and threats, the influence of destructive youth subcultures, and information risks.

The analysis of factors of formation of civil identity of students allowed us to establish their level character, objectivity and subjectivity of manifestation, positive and negative direction of influence. It is necessary to take into account dialectics in revealing the essence of the impact of factors that affect the social attitudes of identity. They can both promote and hinder the strengthening of identity. Thus, the history of the collapse of the Soviet Union, accompanied by an identity crisis, is assessed as a negative factor. At the same time, the common glorious historical past of our country stands out as a significant positive factor of national solidarity.

The factors presented at the global, national, personal and educational levels are dynamic, changing in the coordinates of time and geographical space.

Of particular importance is the consideration of this problem at the global level, since general civilizational factors and trends, although with certain specifics, are manifested in the development of different countries. The globalizing processes of international integration and large-scale communication, intensified by rapid digitalization, are accompanied by the development of the ideas of multiculturalism [14]. Deep integration contributes to the unification and rapprochement of different cultures, enriching them with new ideas, knowledge, and technological innovations, including in the field of security. At the same time, in the context of globalization, some trends affect the inner world of a person, the definition of his own «I», national-cultural and civilizational affiliation. The desire to preserve their national identity, culture and the development of a multiculturalism policy aimed at preserving and developing cultural differences in different countries is increasing. The parallel existence of cultural ethnic groups based on the principles of tolerance contributes to their friendly communication within the universal contours of mass culture. However, the situation of multiculturalism often leads to the dominance of cultural and national forms of self-determination at the expense of legal ones, causing social conflicts and threats to stability.

The factors of the formation of civil identity at the national level reflect the state specifics of Russia, for which it becomes fundamental (Vladimir Putin). Modern Russia is at the stage of actively seeking its position in the international community, experiencing the pressure of globalization and the consequences of national catastrophes of the XX century. The crises of civil identity with the development of Russia and the collapse of the USSR continue and are associated with internal risks of interethnic, inter-confessional, interregional disunity, the search for a common idea of sustainable development, non- 
compliance with generally accepted norms, and growing social inequality. In the situation of the instability of the social institutions of the country, students experience the uncertainty of value orientations. The absence of a stable community of national interests and mutual obligations of the individual leads to a decrease in social trust as the most important condition for joint activities. Civil identity unites the entire population of Russia and acts as a decisive factor in the stability of the state on the way to sustainable development. Its formation within the framework of life safety training is aimed at the formation of self-consciousness of the student's personality as a citizen of his country, distinguished by multiculturalism, that is, taking into account the diversity of social attitudes and values of national, confessional, regional collective self-consciousness. In the system of positive factors of civil identity formation, the following are distinguished: a) a common historical past and aspiration to the future related to sustainable development, solving national security problems; b) a common language as a means of effective communication; c) a common political, economic and legal culture; d) common emotional and value attitudes to key events in Russia (the Immortal Regiment campaign).

When considering the factors of the formation of civil identity at the personal level, it is necessary to take into account the psychophysiological characteristics of students. The adolescent period is characterized by the activity of their life self-determination (L.I. Bozhovia, D.B. Elkonin, D.I. Feldstein), interest in the social problems of the country and the search for their place in social reality, the development of value orientations and relationships, life meanings. There is a desire for a collective solution of socially significant problems. Rapid social changes, the activity of students that are not demanded by society is replaced by social indifference, the birth of a sense of uncertainty in the world of growing problems and threats, the inability to adequately assess them and develop rational solutions alone. There is a growing desire to participate in the youth subcultures, gaining understanding and interest in themselves there.

Overcoming social negativity is associated with the implementation of the ideas of subjectivity-the view of the individual as a subject of life $[8,19]$; the formation of a cultural personality of a safe type of behavior [13]. The objectively increased influence of man on the historical process, which is characteristic of post-industrialism, demands from him a colossal responsibility. Having a culture of security that includes a stable civic identity, the person of the future is aware of his responsibility for personal, public, national, and global security; he understands the need for self-discipline. Life self-determination is formed in the process of socialization, which means personal formation based on the appropriation of social values and ethical norms shared by the vast majority of society. In this regard, the leading factors in the formation of civil identity at the personal level should include: a) support for social activity and initiative of students; b) development of the ability to form their attitude to social problems and events in the country; c) awareness of their own needs and interests in the context of progressive social development and their legitimate protection; d) readiness for independent decision-making and their creative, responsible implementation; e) openness to various forms of social communication and association around common problems, ideas, values, where personal individuality is manifested.

In the educational sphere in the field of life safety, as well as in the entire pedagogical system, the negative factors of the formation of civil identity for a long time were manifested in the following: a) the lack of scientific understanding of its essence and significance among the pedagogical community; b) the lack of a clearly defined formulation of the social order in the educational targets; c) the devaluation of social values in the educational environment; d) the lack of value and worldview aspects of identity in the context of education, the priority of applied aspects of education over cultural studies; e) the weak methodological development of the issue in educational practice. According to A.G. Asmolov, it was these prerequisites that determined the relevance of the transition to a 
new strategy of education - the social construction of civil identity as a basic prerequisite for strengthening statehood [15]. This attitude is reflected in the current Federal State Educational Standards of General Education, where it is noted that the formation of civil identity is designed to ensure the integrity of the student's identity as a citizen of a multicultural country based on universal values.

By implementing the ideas of humanization, integration, and problematization, education in the field of life safety makes a significant contribution to the formation of civil identity based on the education of active citizenship of schoolchildren. In our view, one of the main tasks of organizing the process of forming a civil identity among students is to select the content of the course «Fundamentals of Life Safety». It was found that the greatest effect is achieved when using educational material on social security, which permeates the entire course of primary and full secondary school, and content on the basics of military service, studied by high school students, for whom civilian identity is of vital importance. The need to ensure social security is associated with numerous threats caused by national, religious, and territorial contradictions; risks of aggressive communities and movements, terrorism and extremism [16], violation of individual rights and freedoms, deepening of the economic crisis, deterioration of the environmental situation. The actual social context of the topic and attention to specific social situations, personal assessments provide deep internal motivation and initiative of students in cognition. The selection of content as a means of forming a civic identity was carried out on the principles of recognizing the integral personality of the student in the unity of the development of his affective, cognitive, and volitional spheres of consciousness. At the same time, the age and psychological characteristics of students of different classes, the properties of students as subjects of activity, and the socio-cultural environment were taken into account. All components of the selected content, including axiological, cognitive, praxiological, and creative experience, are related to the structure of civic identity. As a result of mastering the content, an internal worldview belief is formed about one's country as a single whole, distinguished by the ethnic diversity of cultures, nationalities, and religions («unity in diversity»), which must be preserved and developed. Existing national traditions mutually enrich each other, so they deserve respect and care. In the course of training, an interest in ensuring social and national security, the military history of the country is formed, civil consciousness and social activity are developed, and the individual is socialized.

In our work, when forming a civic identity, priority was given to a promising project method that reflects a system-activity approach in education [17]. Presenting an effective mechanism for optimizing the educational process, project-based training provides for a special organization of the educational process associated with the activation of creative activity, increasing the independence of students, and intensive communication (I.A. Kolesnikova, M.P. Gorchakova-Sibirskaya). In our opinion, training, which involves the systematic implementation of various types of educational projects, should become a systematizing factor in the formation of civic identity in the course «Fundamentals of Life Safety».

Educational projects involve the relationship between regular and extra-curricular work, which can consolidate efforts in the education of schoolchildren [18]. By participating in project activities, each of them forms their civic position, which is expressed in specific cases. Here you can express your attitude to society, find ways to realize your «I» in interaction with the world around you. Through participation in information and cognitive, creative, practice-oriented projects developed and tested in the course of master's training at the Minin Nizhny Novgorod State Pedagogical University, teenagers learn about the real world, form moral and social values and attitudes, and civic consciousness. In the course of working with information, critical thinking develops, when students learn to think based on real, and not fake, data about the historical and cultural features of their citizenship, their 
identification in civil society. The ability to resist the aggressive influence of multiculturalism trends, to solve social and interpersonal conflicts based on tolerance is formed.

A survey conducted among teachers (105 people) indicates an almost unanimous high assessment of the potential of the course «Fundamentals of Life Safety» in the formation of civil identity (96\%). $85 \%$ of them believe that a civic identity will provide graduates with favorable opportunities in solving future vital problems. Also, they (68\%) note its advantages in achieving social mobility of future graduates («social elevator»). Teachers understand the need for active pedagogical activity in the formation of civil selfdetermination of students. Many of them (76\%) in the classroom address issues of spiritual and moral education, healthy and safe lifestyle, learning the rules of safe behavior at social risks. The work on the projects is highly appreciated. Judging by the responses, project activity has a very positive impact on the organization of the entire educational process $(88 \%)$, only $6 \%$ do not see any prospects in it, and $6 \%$ show indifference. According to the majority of teachers, project-based training provides a more effective formation of motivation $(90 \%)$ and assimilation of content $(82 \%)$. Besides, the value-semantic and subject-content results are supplemented by such important pedagogical effects as the development of new forms of interpersonal communication by students.

\section{Conclusions}

As a result of the conducted research, conclusions are drawn about the necessity and relevance of the formation of a civil identity, revealed through the personal selfdetermination of a person within the civil community of the state, which has a personally significant meaning for everyone. The formation of a civil personality is influenced by many factors, systematized based on a level approach: global, national, personal. Special attention is paid to education in the field of life safety, which has a high socio-pedagogical potential, which allows successfully forming the civic qualities of students. Based on the selected principles, the content was selected and the project method of its development was determined. The implementation of educational projects in the classroom and extracurricular activities showed the prospects of project-based learning, confirmed by the results of a survey of teachers. The abilities of students acquired based on the acquired values, knowledge, and ways of activity become the basis of the expected social effects associated with the strengthening of civic identity.

\section{References}

1. I.S. Kuzmenko, Value and objective aspects of solidarity in the context of global transformation, [Electronic resource] https://doi.org/10.24158/fik.2020.5.1 (2020)

2. I.A. Tagunova, World trends in the development of school education, Pedagogy, 6, 106-113 (2019)

3. O.N. Yanitsky Challenges and risks of globalization. Seven theses, Sociological research, 1, 29-39 (2019)

4. L.V. Bayborodova, Local history activity as a means of educating the civic identity of rural schoolchildren, Bulletin of the Academy of Children's and Youth Tourism and Local History, 1(122), 123-133 (2017)

5. V.N. Moshkin, S.V. Petrov, Pedagogical tasks as a means of teaching schoolchildren the basics of life safety, OBZH: Fundamentals of life security, 4, 18-22 (2020) 
6. V.P. Solomin, S.V. Abramova, P.V. Stankevich, The main priorities of the development of higher pedagogical education in the field of life safety [Electronic resource] https://moluch.ru/th/3/archive/14/392/ (2015)

7. N.S. Burlakova, V.I. Oleshkevich, Applied cultural and historical psychology before the Challenges of modernity, National Journal of Psychology, 3(39), 3-12 (2020

8. Yu.R. Efremova, N.A. Simbirtseva, Cultural identity of bilingual children: psychological and pedagogical aspect, Pedagogical education in Russia, 5, 146-153 (2020)

9. V.V. Znakov, Self-creation of a person - a new stage in the development of the psychology of the subject, Bulletin of the Saint Petersburg University. Psychology, 9(2), 112-122 (2019)

10. V.P. Borisenkov, O.V.Gukalenko, V.N. Pustovoitov, Multicultural educational space of the university as a medium for the formation of citizenship, Pedagogy, 2, 44-51 (2018)

11. A.V. Gulevich, A.V. Rudakov, Patriotic education as a strategic direction of the state policy of the Russian Federation on strengthening national identity, Bulletin of the Russian Nation, 3, 9-24 (2019)

12. Y. Tarada, Education Research Highlights [Electronic resource] https://www.edutopia.org/article/2018-education-research-highlights (2018)

13. G.S. Kamerilova, M.A. Kartavykh, I.A. Voronina, Formation of civil identity as an actual problem of modern education, Problems of modern pedagogical education: collection of scientific papers, 111-114 (2019)

14. R.F. Bemalyan, Multiculturalism: the essence and evolution of political practice, Bulletin of the Russian Nation, 2, 102-111 (2019)

15. A.G. Asmolov, M.S. Guseltseva, On the value sense of socio-cultural modernization of education: from reforms to reformation, Vestnik Bulletin of the Russian State University for the Humanities, 1, 18-43 (2019).

16. S.E. Sergeev, Study of the formation of professionally important qualities of a psychologist necessary for the re-socialization of adolescents who have been subjected to religious and extremist influence, Vestnik of Minin University, 9(1) (2021)

17. E.Yu. Glazyrina, E.V. Dongauzer, T.A. Nezhinskaya, Project activity as a condition for the formation of civil identity of students, Pedagogical education in Russia, 3, 16$25(2020)$

18. L.M. Grimovskaya, Development of cognitive abilities of children in project activities on environmental topics, Vestnik of Minin University, 8(2) (2020) 